\title{
A Robust Tool for Monitoring and Synchronizing Smart Grid through Adaptive Comb Filter
}

\author{
P. Murugesan ${ }^{1}$, S. Prabakaran ${ }^{2}$ \\ ${ }^{1,2}$ Dept of EEE, SCSVMV University, Kanchipuram, Tamil Nadu, India
}

\begin{tabular}{l} 
Article Info \\
\hline Article history: \\
Received Nov 30, 2018 \\
Revised May 01, 2019 \\
Accepted Nov 21, 2019 \\
\hline Keyword: \\
Adaptive Comb Filter (ACF) \\
Power Quality (PQ) \\
Enhanced Phase Locked Loop \\
(EPLL)
\end{tabular}

\begin{abstract}
The power system signals are often polluted with harmonics and noise as a result of nonlinear load. These non stationary signals has to be monitored carefuly before it propagates as a grid problem. This article aims on the design of adaptive comb filter, which extracts the amplitude, frequency and phase components of the signal with respect to time for better monitoring purpose and extraction of harmonic components for suppressing the contamination present in the signal for synchronizing the smart grid. The main objective of the current work is to reduce the harmonic distortion present in the signal by synchronizing the grid through adaptive comb filter. The response of the filter is compared with enhanced phased locked loop to describe the superior characteristics of adaptive comb filter. The results indicate that ACF tracks the transient (dynamic) and steady state behaviour of the signal effectively, efficiently and accurately.
\end{abstract}

Copyright $(0) 2018$ Institute of Advanced Engineering and Science. All rights reserved.

\section{Corresponding Author:}

\section{P. Murugesan,}

Department of Electrical and Electronics Engineering,

SCSVMV University,

Kanchipuram, India.

Email: murugesh78_au@yahoo.co.in

\section{INTRODUCTION}

The monitoring of electrical parameters and suppression of harmonics is necessary to improve the quality of power signal. Timely control and protection makes the electrical grid equipment from unexpected failure.The nonlinear load mainly power electronic devices disorts the current waveform and termed as harmonics. Harmonics are integer multiples of fundamental frequency that are non stationary in nature. A typical problem caused by harmonics is overheating which directly reduce the efficiency of the system and indirecty reduces the useful life of the equipment. On the other hand, to satisfy the power demand the renewable energy sources are used as an alternate source for generating electric power,these power are syncronised and fed to the electric grid via bulky power electronic devices, transformers and controllers. The conventional controllers in collaboration with transformation techniques are used to extract the fundamental components that are complex in the sense, tunning of controller parameter is not self adaptability. In this scenario a robust tool for monitoring and synchronizing the grid is essential to improve the power quality and it is acheived through adaptive comb filter [1].

There are variety of signal processing techniques exist and used in the past decade to track the variation of signal with respect to time. Fourier Transform (FT) is a transformation technique that converts the information of time domain into frequency domain of the analysing signal.The spectral frequencies are analysed in the better way with total loss of time domain information and it is difficult to determine when or where the particular dynamic event occurs. To overcome the drawbacks, Short Time Fourier Transform (STFT) was evolved. It is a windowing technique analyses the signal with respect to window width for a small section of time period.The STFT gives better frequency response analyses with respect to time but it endures with the consequence of aliasing and time window effect.These effects reduce the effectiveness of the technique to analyses the dynamic nature of the signal[2]-[4]. 
Hilbert Transform (HT) detects the magnitude variation as an envelope of the non stationary PQ signal. Yet, the frequency information is lost and phase information is insignificant [5]. In [6] and [7], Wavelet Transform (WT) has been used to decompose the signal into different sets of frequency has approximate and detailed version of the signal. WT suffers form several pitfalls including range of sampling frequency, choice of selection of mother wavelet, number of levels and edge effects. WT in combination with Parseval's theorem, estimates the energy of the signals and the data are unique for each PQ disturbances. These datas are used in artificial neural networks to characterize and classify PQ events. The main drawback is time consuming and huge data to be analysed, processed and stored [8] and [9].

A number of algorithms are reported in [10]-[14], S transform, TT transform, Kalman filtering, adaptive infinite impulse response line enhancer and fuzzy logic controller had been proposed to characterize the PQ signal instantaneously. In [15]-[17], Enhanced Phase Locked Loop (EPLL) is used as detecting tool which produces the sluggish response under transient condition. Although each technique has specific merits, none reported simple, robust and good frequency varying environments for smart grid synchronization.The ACF is good choice compared to other methods, whose applications are parameter estimation such as magnitude, phase angle and frequency, decomposition of individual harmonic components, estimation and suppression of harmonics using ACF is proved to be excellent.

The literatures [1]-[27] do not report the synchronization of power grid through ACF. The comparison of responses of EPLL and ACF for PQ disturbance detection is not reported. This work suggests ACF is a better tool/ technique for smart(er) grid synchronization.

\section{THE PROPOSED METHOD/ALGORITHM}

The algorithm is implemented through the following steps.

1. Generation of Synthetic signal as per IEEE standard.

2. APF is realized in MATLAB Simulink using these equations

$$
\begin{aligned}
\ddot{x}_{k}(t) & =-\theta_{k}^{2}(t) x_{k}(t)+2 \zeta_{k} \theta_{k}(t) e(t) \\
\dot{\theta}_{k}(t) & =-\gamma_{k} x_{k}(t) \theta_{k}(t) e(t), k=1,2, \ldots, n \\
e(t) & =r(t)-\sum_{k=1}^{n} \quad \dot{x}_{k}(t) \\
\gamma_{k} & =\frac{\gamma_{0}}{\mu+N\left(x_{k}^{2} \theta_{k}^{2}+\dot{x}_{k}^{2}\right)}
\end{aligned}
$$

3. Where $\gamma_{0}=\alpha \mathrm{N}, \zeta_{\mathrm{k}}=\zeta_{0} / \mathrm{k}^{2}, \mu$ and $\mathrm{N}$ are positive real constant. $\mathrm{k}$ is the order of harmonic or sub filters used. The values of constant are chosen. $\zeta_{0}=1.25, \mathrm{~N}=2500$,

$\alpha=5500$ and $\mu=0.01$

4. The frequency limiters are adjusted to operate within the range of $\pm 25 \mathrm{~Hz}$ around the nominal frequency.

5. The amplitude and the phase of kth component of the signal is given by

$$
\left(\overline{\mathrm{x}_{\mathrm{k}}^{2}} \overline{\theta_{\mathrm{k}}^{2}}+\overline{\mathrm{x}_{\mathrm{k}}^{2}}\right)^{\frac{1}{2}}=\mathrm{A}_{\mathrm{k}} \text { and } \varphi_{\mathrm{k}}(\mathrm{t})=\left\{\begin{array}{l}
\arccos \left(-\frac{\theta_{\mathrm{k}} \mathrm{x}_{\mathrm{k}}}{\mathrm{A}_{\mathrm{k}}}\right) \quad \dot{\mathrm{x}_{\mathrm{k}}}>0 \\
2 \pi-\arccos \left(-\frac{\theta_{\mathrm{k}} \mathrm{x}_{\mathrm{k}}}{\mathrm{A}_{\mathrm{k}}}\right) \dot{\mathrm{x}_{\mathrm{k}}}<0
\end{array}\right.
$$

6. APF estimates the attributes of input signal such as amplitude $\left(A_{k}(t)\right)$, frequency $\left(\omega_{k}(t)\right)$, phase $\left(\phi_{k}(t)\right)$ and frequency component of signal $A_{k} \sin \phi_{k}(t)$.

7. The first order Low pass filter with the transfer function of $1 /(\tau s+1)$ are added posterior to the estimator to obtain the smooth output, where $\tau=1 /(2 \pi 10) \mathrm{s}$

8. Analysis of PQ signals [18]-[19].

\section{RESEARCH METHOD}

Figure 1. shows the Schematic representation of the ACF bank. In [20], the ACF bank is composed of $n$ coupled parallel sub filter units, the units can be extended according to the requirement of decomposition. Each unit consists of specific frequency band, so it passes one particular frequency at a time interval and suppress or rejects all other frequencies including noise and distortion hence it is called as Adaptive Notch Filter (ANF). Figure 2. represents the design description of $\mathrm{k}^{\text {th }}$ parallel sub-filter as per the dynamic equations listed in the algorithm. The ACF provides all the information about signal such as amplitude, frequency, phase and individual harmonic components. This information is used by any converter to synchronize the grid in closed loop control. 


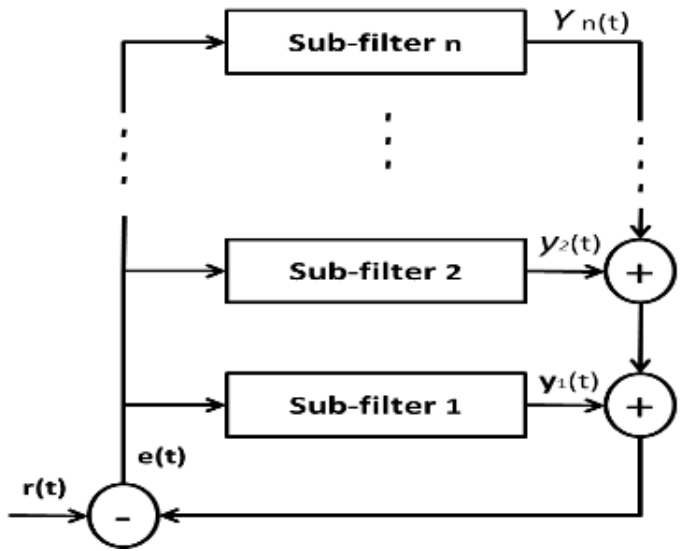

Figure 1. Schematic representation of ACF

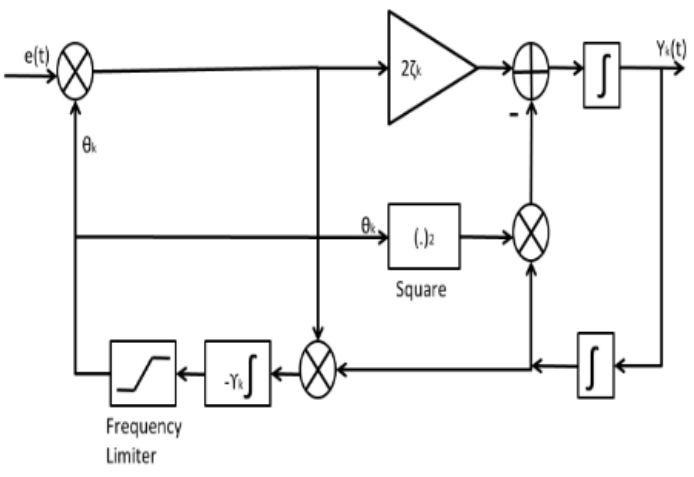

Figure 2. Design description of kth parallel Sub-filter.

\section{RESULTS AND ANALYSIS}

\subsection{Initiatory Performance}

The input signal $x(t)$ generated using Matlab code depicited in the equation (1) and shown in Figure 3. The signal is processed through simulink blocks of ACF. The ACF consist of five sub units connected in parallel which estimates the signal attributes. The ACF extracts the amplitude and frequency of the input signal as shown in Figure 4 and Figure 5. The amplitudes are $A_{1}=1.0$ p.u, $A_{2}=0.8$ p.u, $A_{3}=0.6$ p.u, $A_{4}=0.4 p . u, A_{5}=0.2$ p.u and the frequency are $F_{1}=50 \mathrm{~Hz}, F_{2}=100 \mathrm{~Hz}, F_{3}=150 \mathrm{~Hz}, F_{4}=200 \mathrm{~Hz}, F_{5}=250 \mathrm{~Hz}$ are estimated by the ACF bank.

$$
\begin{gathered}
x(t)=1.0 * \sin (2 * p i * 50 * t)+0.8 * \sin (2 * p i * 100 * t)+0.6 * \sin (2 * p i * 150 * t) \\
+0.4 * \sin (2 * p i * 200 * t)+0.2 * \sin (2 * p i * 250 * t) ;
\end{gathered}
$$

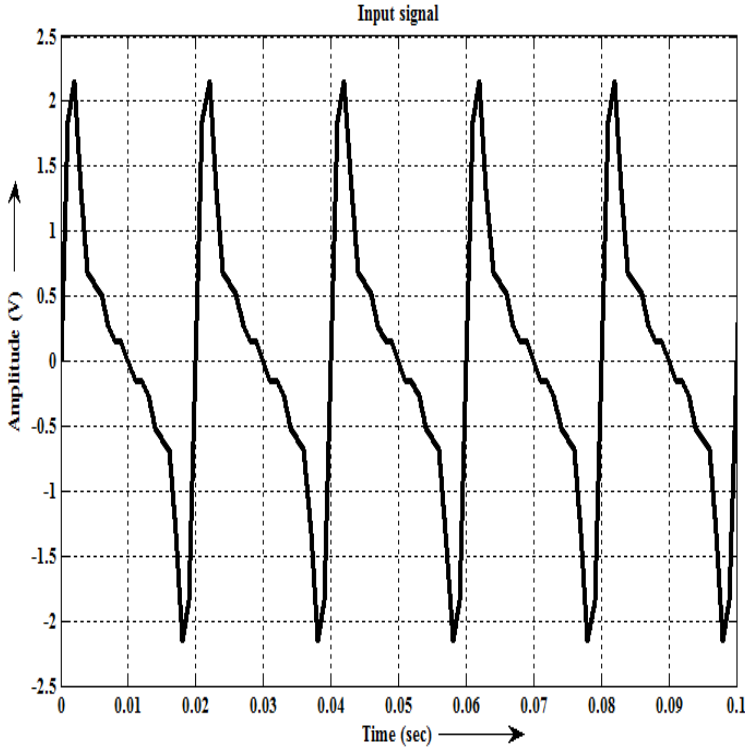

Figure 3. Input signal to ACF

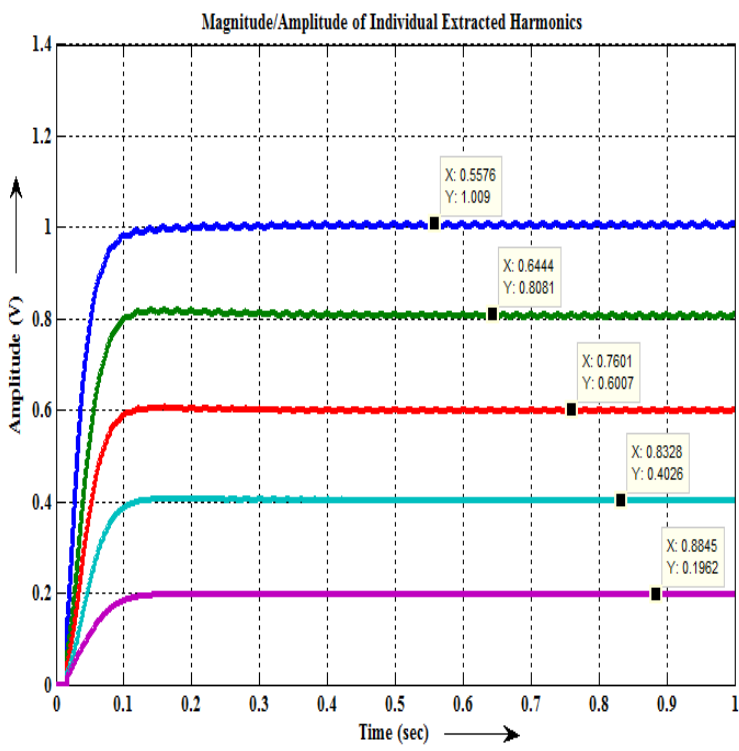

Figure 4. Amplitude estimation of ACF 


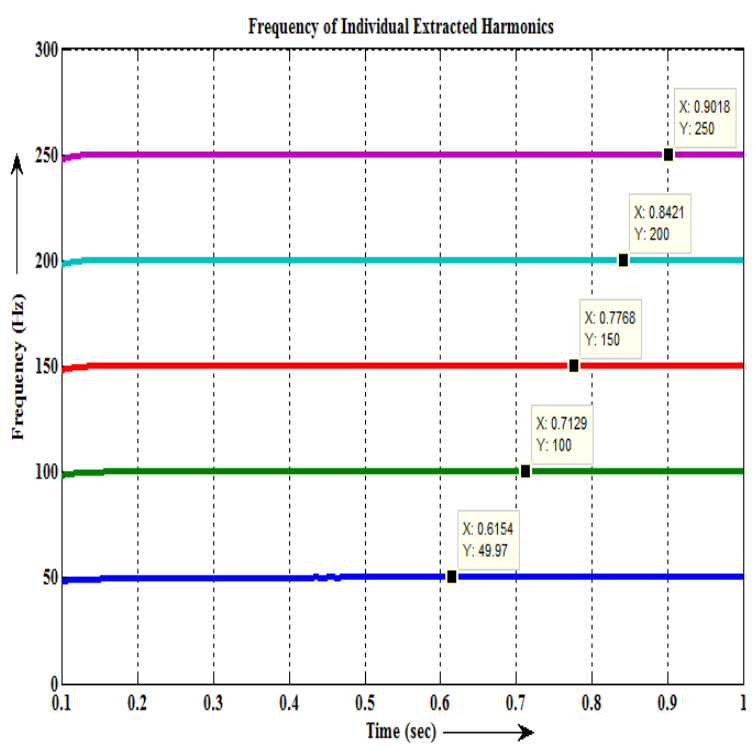

Figure 5.Frequency estimation of ACF
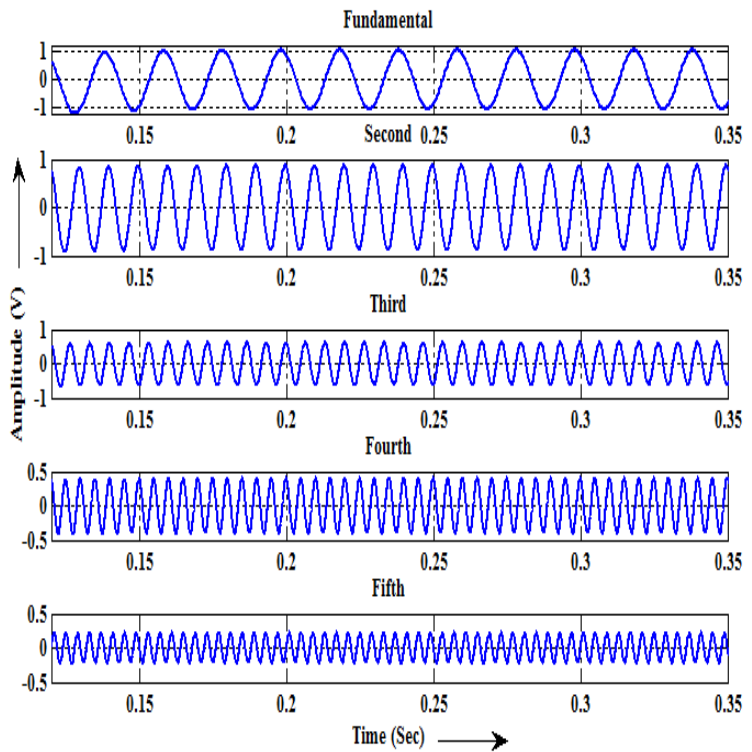

Figure 6. Extracted individual Harmonic component

Figure 6 shows the extracted individual harmonics component of highly disorted input signal shown in Figure 1. The output of ACF decomposes the input signal into its individual Harmonic components. The individual Harmonic component tracks its amplitude and its frequency component accurately and precisely. Figure 7 shows the phase of extracted harmonics component of ACF. The order of harmonic component can be recognized from the phase response. The phase characteristics is a train of spikes describes the presence of harmonic component in the signal. For particular time interval say 0.02 to $0.04 \mathrm{sec}$ the fundamental component has only one peak (ramp), second harmonics has two peaks and third harmonics has three peaks and so on.
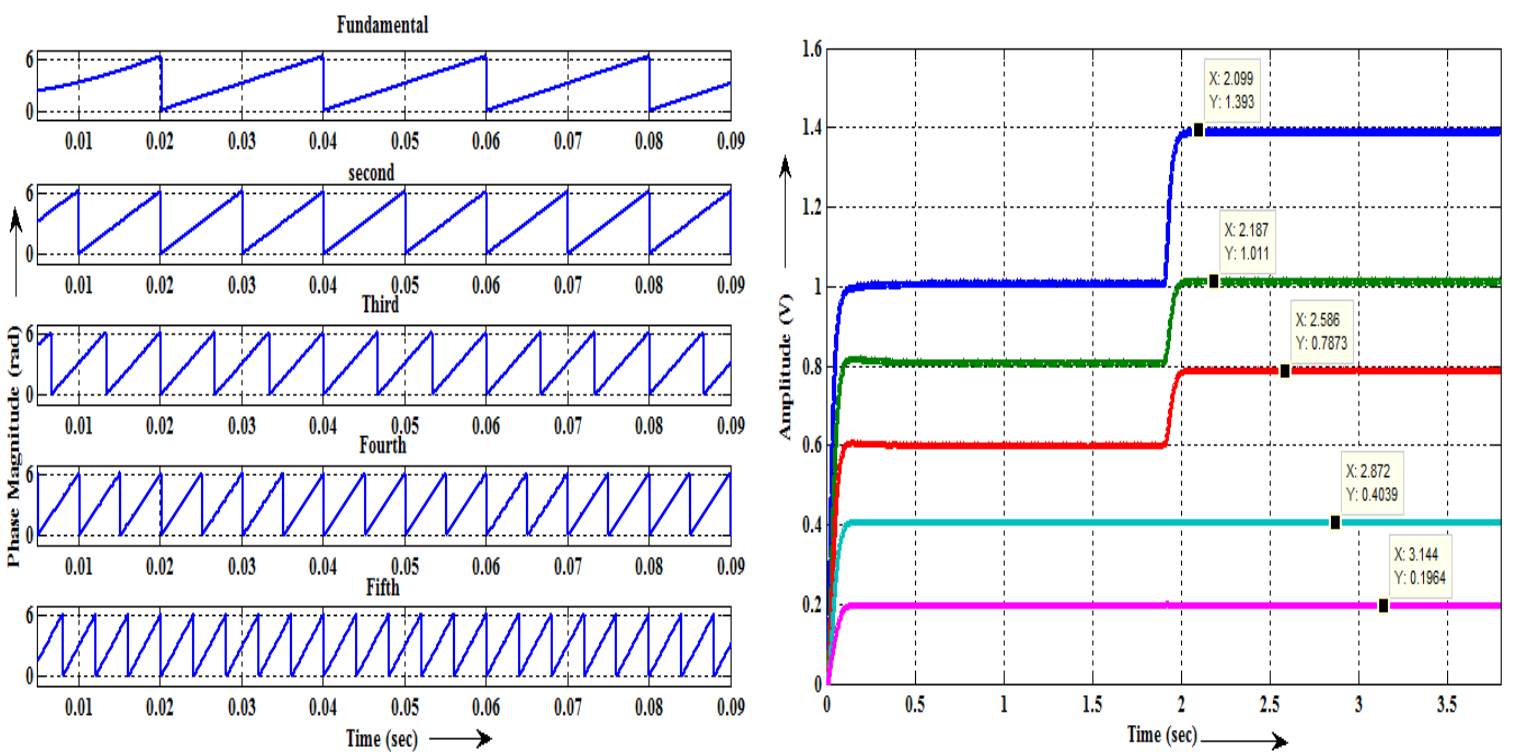

Figure 8.Tracking of amplitude changes

Figure 7. Phase of extracted Harmonic component

\subsection{Tracking characteristics}

\subsubsection{Tracking of Amplitude changes}

The tracking feature of the designed ACF is tested by changing the amplitude of the input signal in equation (1). Initial Amplitude is $\mathrm{A}_{1}=1.0 \mathrm{p} . \mathrm{u}, \mathrm{A}_{2}=0.8 \mathrm{p} . \mathrm{u}, \mathrm{A}_{3}=0.6 \mathrm{p} . \mathrm{u}, \mathrm{A}_{4}=0.4 \mathrm{p} . \mathrm{u}, \mathrm{A}_{5}=0.2 \mathrm{p} . \mathrm{u}$ till time $\mathrm{t}=1.9 \mathrm{sec}$ thereafter the amplitude changes are tracked and depicited in Figure 8 has $A_{1}=1.4 p . u, A_{2}=1.0 p . u, A_{3}=0.8 p . u$ and other amplitudes such as $\mathrm{A}_{4}=0.4 \mathrm{p} . \mathrm{u}, \mathrm{A}_{5}=0.2 \mathrm{p}$.u remains constant. 


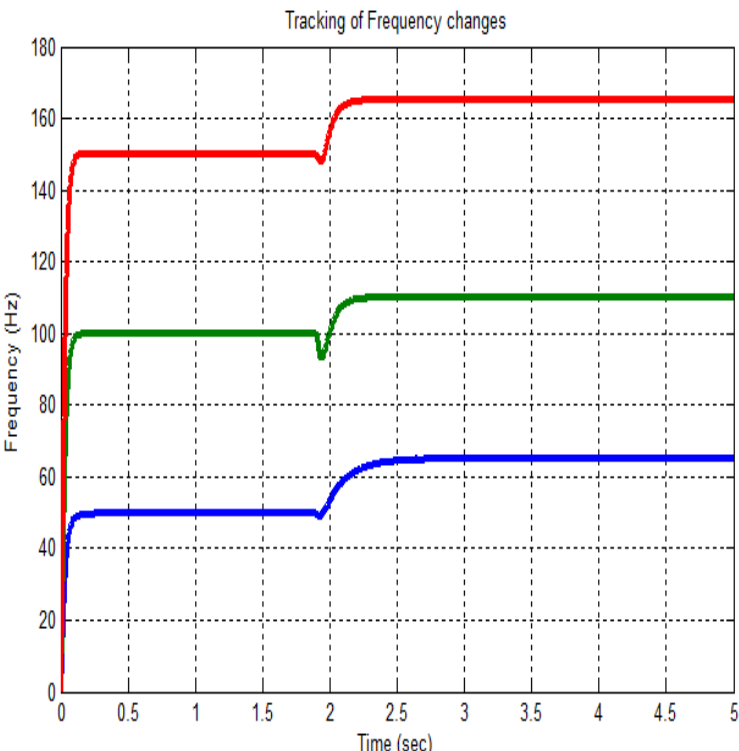

Figure 9. Tracking of frequency changes

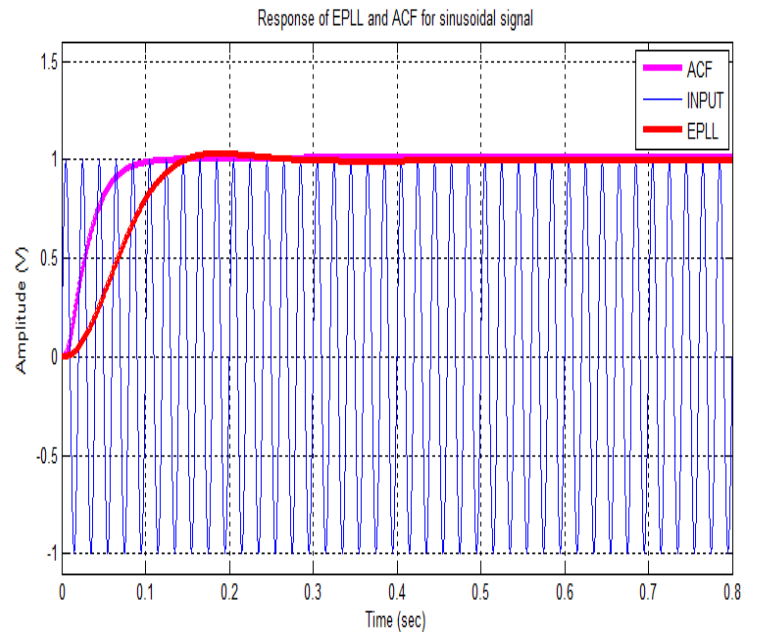

(a) sinusoidal signal

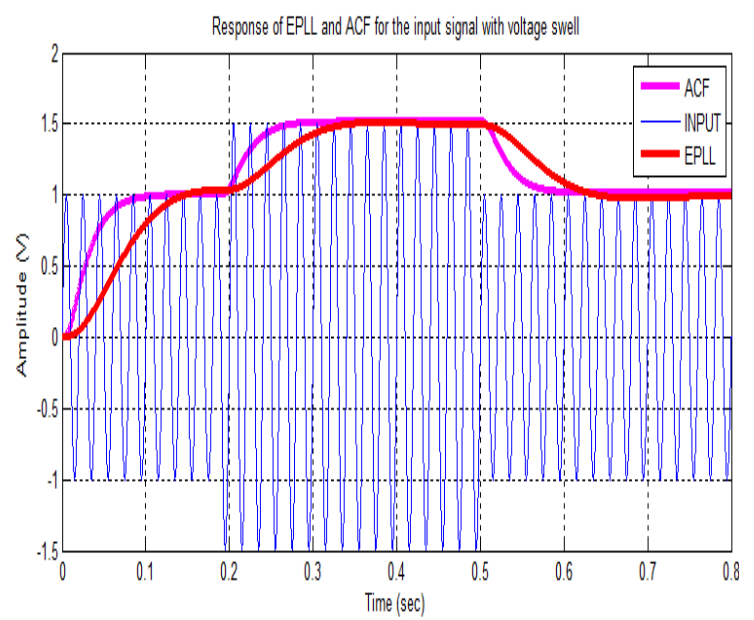

(c) signal with swell

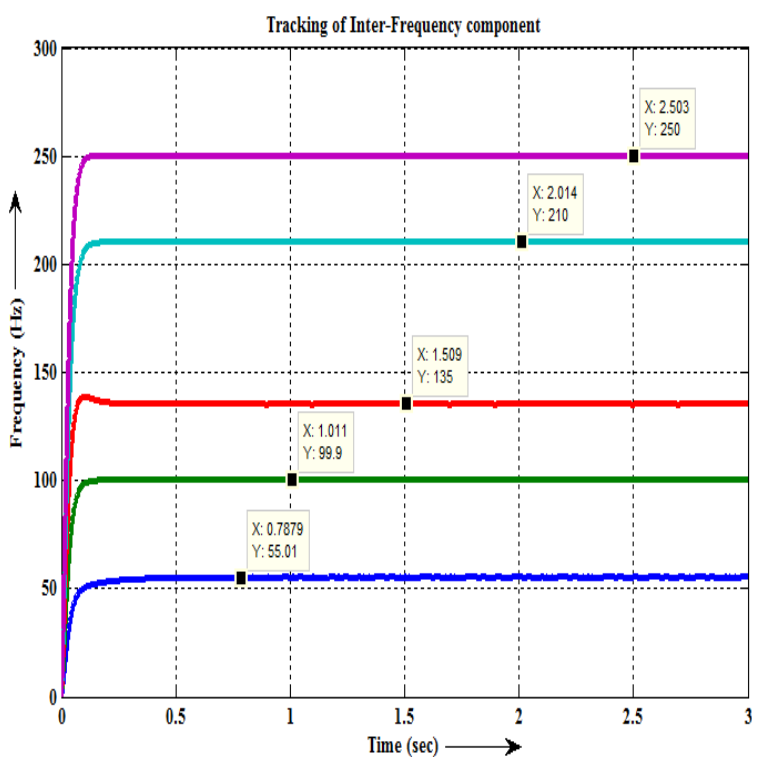

Figure 10.Tracking of inter-frquency components

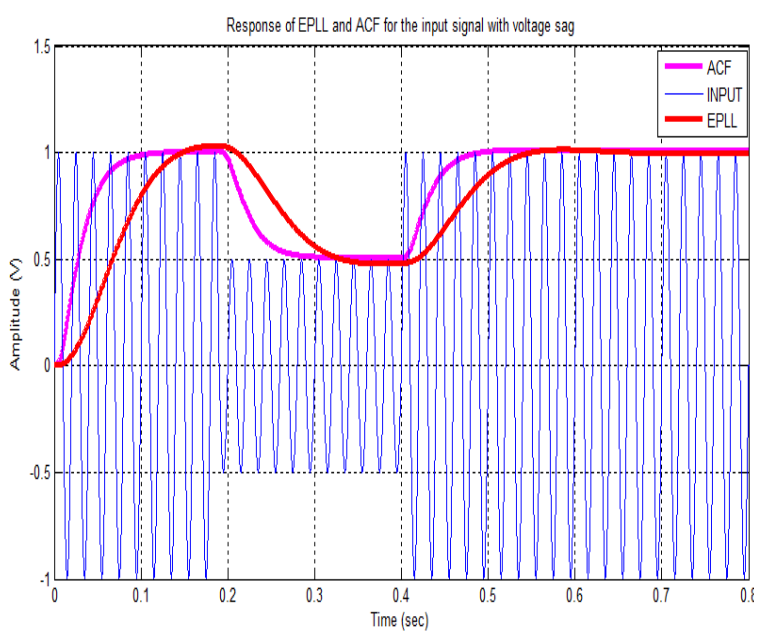

(b) signal with sag

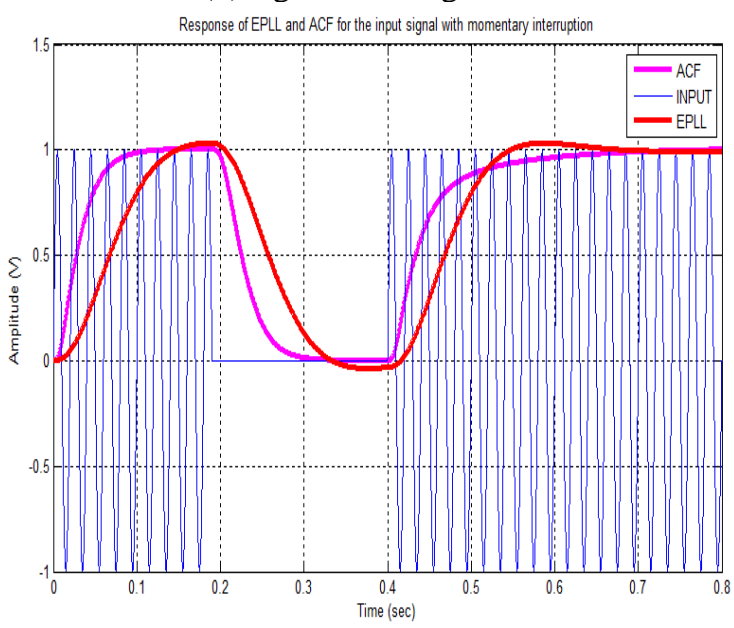

(d) signal with momentary interruption

Figure 11. (a-d) The comparision of dynamic tracking of ACF and EPLL of PQ events.

4.2.2. Tracking of Frequency Changes

The tracking feature is tested with the designed ACF by changing the frequency of the input signal after $t=1.9 \mathrm{sec}$. Initial Frequency $\mathrm{F}_{1}=50 \mathrm{~Hz}, \mathrm{~F}_{2}=100 \mathrm{~Hz}$ and $\mathrm{F}_{3}=150 \mathrm{~Hz}$. The transient and steady state behavior 
of the filter outputs are displayed in Figure 9.The transient response is shown during the time interval from $\mathrm{t}=1.9 \mathrm{sec}$ to $\mathrm{t}=2 \mathrm{sec}$ after the time $\mathrm{t}=2 \mathrm{sec}$ steady state response is observed with the frequency changes $\mathrm{F}_{1}=65$ $\mathrm{Hz}, \mathrm{F}_{2}=110 \mathrm{~Hz}$ and $\mathrm{F}_{3}=165 \mathrm{~Hz}$.

\subsubsection{Tracking of Inter-frequency}

The input signal consists of harmonics and interharmonics which are given to ACF, whose amplitude and frequency of is $A_{1}=1.0$ p.u, $A_{2}=0.8$ p.u, $A_{3}=0.6 p . u, A_{4}=0.4 p . u, A_{5}=0.2 p . u$ and $F_{1}=55 \mathrm{~Hz}, F_{2}=100 \mathrm{~Hz}, F_{3}=135$ $\mathrm{Hz}, \mathrm{F}_{4}=210 \mathrm{~Hz}, \mathrm{~F}_{5}=250 \mathrm{~Hz}$. Each $\mathrm{ACF}$ unit has a specific band of frequency, so that each unit will extract the particular range of frequency present in the signal. Thus, any inter-frequency component present within the frequency band will be extracted by that particular unit of ACF as shown in Figure 10. The inter-frequency component $55 \mathrm{~Hz}, 135 \mathrm{~Hz}$ and $210 \mathrm{~Hz}$ are extracted by first, third and fourth units of ACF faithfully.

\subsection{Comparision of EPLL and ACF Characteristics}

\subsubsection{Dynamic tracking ability}

Figure 11(a) shows the instantaneous tracking ability of ACF and EPLL for the pure sinusoidal waveform. In ACF the tracking starts with in half a cycle and attains the steady state in third or fourth cycle, where as in EPLL the tracking starts with delay of two cycles and attains the steady state after seventh cycle. Both the technique detects and tracks the PQD such as sag, swell and momentary interruption instantaneously yet, ACF detects precisely and the simulation results in [27] are compared and depicited in Figure 11 (b-d). The estimator ACF and EPLL estimates and tracks the amplitude with respect to the disturbances, Figure 11(b) shows $60 \%$ of sag since the value of magnitude is below 1.0p.u during the time span 0.2 to $0.4 \mathrm{sec}$. Figure 11(c) identified as $70 \%$ of swell since the value of magnitude is above 1.0 p.u during the time period 0.2 to $0.5 \mathrm{sec}$. Figure 11(d) characterises as $100 \%$ power failure during the time interval of 0.19 to 0.4 sec since the value of magnitude reaches zero it is recognised as interruption.

\subsubsection{Speed of response of EPLL and ACF}

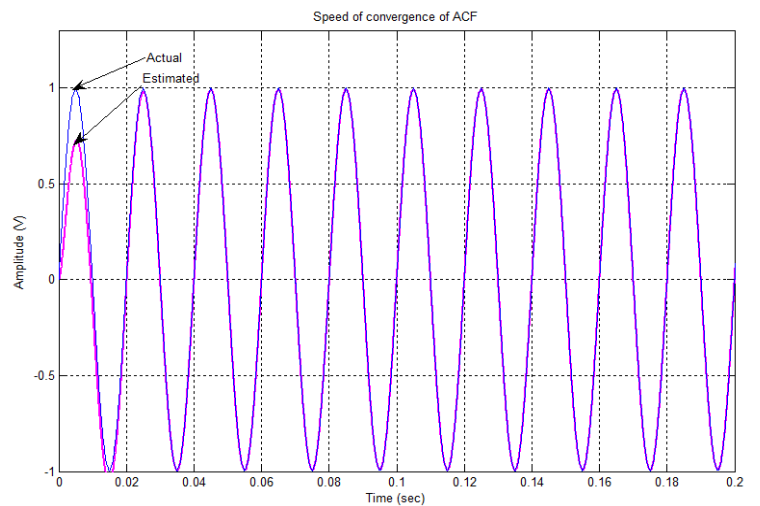

Figure 12. Actual and estimated fundamental component using ACF

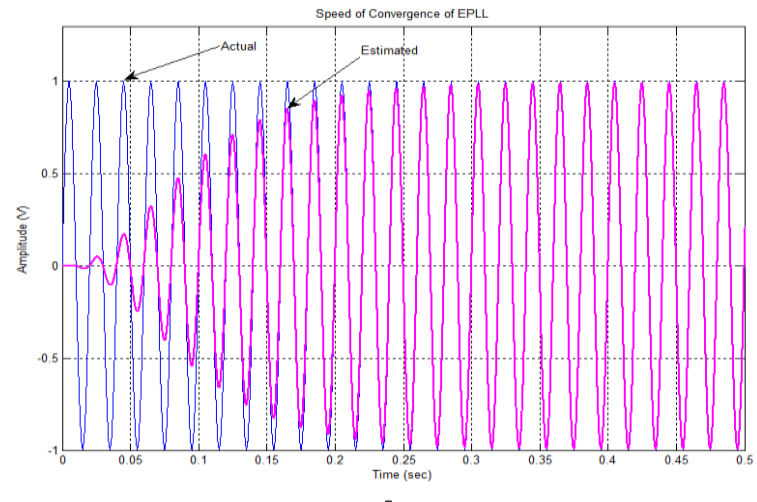

Figure 13. Actual and estimated fundamental component using APLL

Figures 12 and 13 represents the speed of convergence of ACF and EPLL of the pure sinusoidal waveform. The estimated output of ACF reaches the actual value in half a cycle and converge at $\mathrm{t}=0.02 \mathrm{sec}$, whereas in EPLL it reaches the actual value at $\mathrm{t}=0.2 \mathrm{sec}$ after fourteenth cycle.Therfore ACF is concluded as fastest response behaviour.

\subsubsection{Noise suppressing/removal characteristics of ACF}

The sinusoidal signal is added with the Gaussian noise of 20 decibel is a noisy input signal to ACF depicited in Figure 14(a). Figure 14(b) represents the filtering characteristics of ACF which suppress the noise and extracts the pure sinusoidal input. 


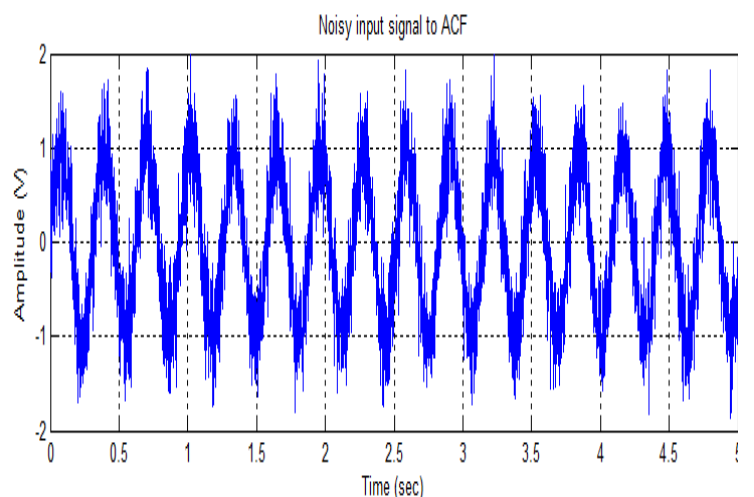

(a)

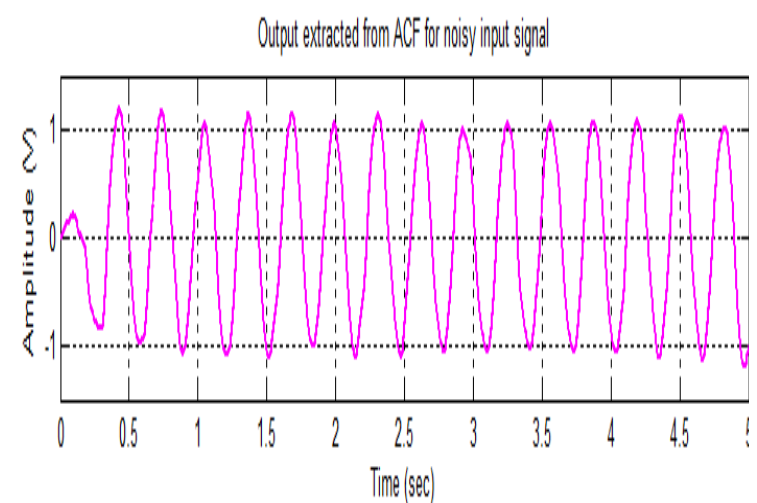

(b)

Figure 14 (a) Noisy input signal to ACF, (b) Filtering characteristics of ACF

\subsection{Grid synchronization}

When the source is connected to the nonlinear load, the source/grid current is highly distorted and they are termed as Harmonics. The Harmonics and interharmonics are spectral components yet, harmonics are integer multiples of fundamental frequency and interharmonics are not integer multiples of fundamental frequencies. These harmonics are to be compensated before it aggravates as fault or breakdown [21]-[27]. Figure 15 shows the grid synchronization of three phase power system through ACF. The power system consists of AC power source with the voltage $100 \mathrm{~V}$, and frequency of $50 \mathrm{~Hz}$ is used. For grid synchronization three pairs of identical ACF's are used.The three phase source Voltages are $\mathrm{Va}, \mathrm{Vb}$ and $\mathrm{Vc}$ and the nonlinear load current IaNL, IbNL and IcNL are measured and passed through each pair of ACF. The ACF extracts and detects all the usefull information embedded in the input signal such as amplitude, frequency and phase of fundamental, individual harmonic and reactive components. These components provide the compensating current signal Ic to grid connected inverter for synchronization. Therefore, the source currents are free from harmonics.

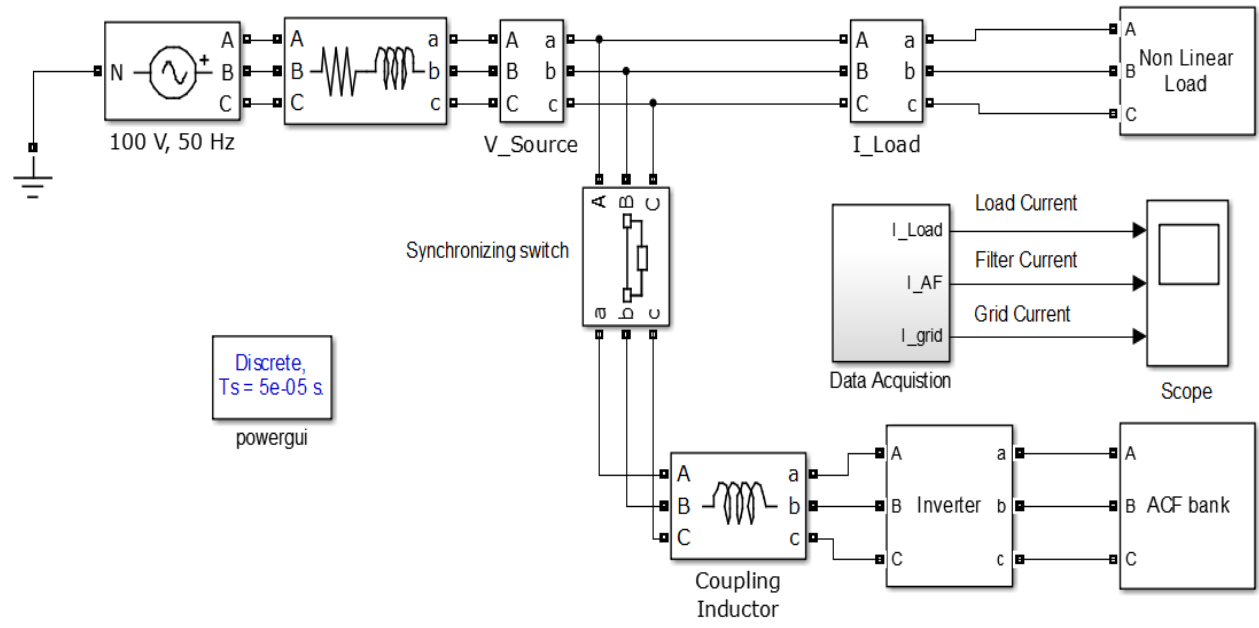

Figure 15. Grid synchronization of three phase power system through ACF

Figure 16(a) shows three phase AC voltage sources of $\mathrm{Va}, \mathrm{Vb}$ and $\mathrm{Vc}$ which supplies the nonlinear load with the amplitude of 100V. Figure 16(b) shows the grid current is polluted by nonlinear load whose magnitude is 2.9 Amps. Figure 16(c) represents the compensating current (Ic) produced by ACF. The synchronizing switch is closed at time $t=0.04 \mathrm{sec}$ is shown in Figure 16(d) after $t=0.04 \mathrm{sec}$ the source current is pure sinusoidal waveform.

The Total Harmonic Distortion (THD) is stepped down from $26.25 \%$ to $1.71 \%$ is depicited in Figure 17(a) and Figure 17(b) of phase current A before and after synchronization through ACF bank. The frequency spectral analysis of signal is carried out by FFT are listed in Table 1 and 2 before and after passing the signal through ACF. The predominant individual harmonic components are h5, h7, h11 and h13 listed in Table 1 is reduced as per IEEE specified limit of less than 3\% are listed in the Table 2 when the signal passed and syncronised through the ACF bank. The magnitude of THD of phase A current of individual harmonic component say, fifth order harmonics (h5) before passing ACF is $22.09 \%$, the compensating current Ic 
produced by ACF reduce the THD to $0.23 \%$. Similarly the seventh order individual harmonic (h7) is reduced to $0.20 \%$ from $10.10 \%$ and keep the grid free from harmonics.

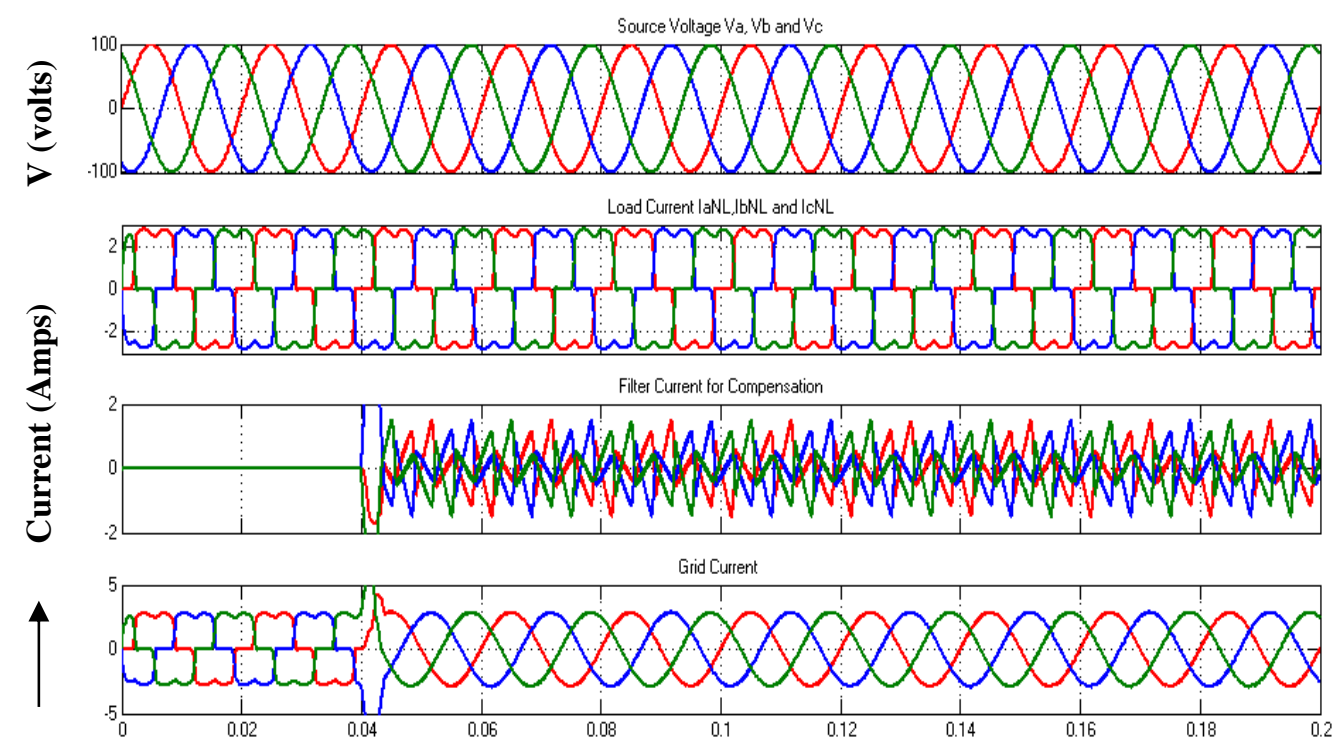

Figure 16 (a) three phase source voltage, (b) Load current, (c) Filtercurrent,and (d) Grid synchronized current.

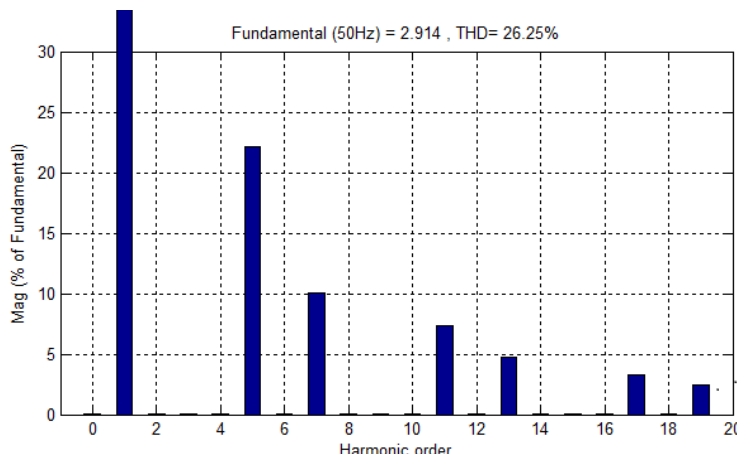

Figure 17(a) THD of phase A current before synchronization

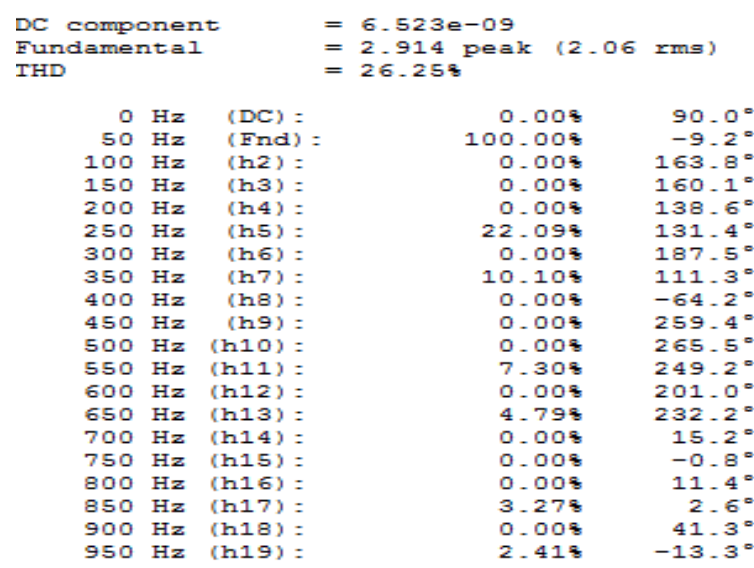

Figure 18. FFT analysis of phase A current before synchronization (snap shot of simulated output)

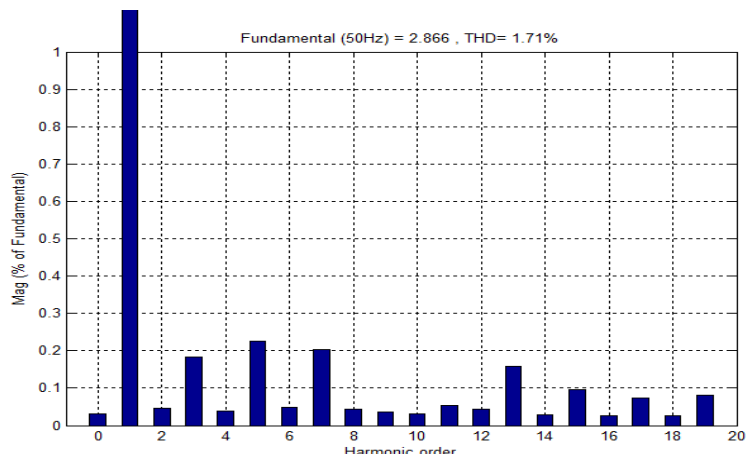

Figure 17(b) THD of phase A current after synchronization through $\mathrm{ACF}$

\begin{tabular}{|c|c|c|c|c|c|}
\hline \multicolumn{3}{|c|}{$\begin{array}{l}\text { DC component } \\
\text { Fundamental } \\
\text { THD }\end{array}$} & \multicolumn{3}{|c|}{$\begin{array}{l}=0.0009098 \\
=2.866 \text { peak (2.027 rms }) \\
=1.718\end{array}$} \\
\hline 0 & $\mathrm{~Hz}$ & $(D C)=$ & & 0.038 & $270.0^{\circ}$ \\
\hline 50 & $\mathrm{~Hz}$ & (Fnd) & & 100.008 & $-0.1^{\circ}$ \\
\hline 100 & $\mathrm{~Hz}$ & $(h 2)=$ & & 0.058 & $-7.1^{\circ}$ \\
\hline 150 & $\mathrm{~Hz}$ & $(h 3)=$ & & 0.188 & $-28.7^{\circ}$ \\
\hline 200 & $\mathrm{~Hz}$ & $(\mathrm{~h} 4)=$ & & 0.048 & $254.3^{\circ}$ \\
\hline 250 & $\mathrm{~Hz}$ & $($ h5 $)=$ & & 0.238 & $159.5^{\circ}$ \\
\hline 300 & $\mathrm{~Hz}$ & $($ h6) $=$ & & 0.058 & $20.8^{\circ}$ \\
\hline 350 & $\mathrm{~Hz}$ & $(\mathrm{~h} 7)=$ & & 0.208 & $205.2^{\circ}$ \\
\hline 400 & $\mathrm{~Hz}$ & $(\mathrm{~h} 8)=$ & & 0.048 & $170.8^{\circ}$ \\
\hline 450 & $\mathrm{~Hz}$ & (h⿻) $=$ & & 0.048 & $84.3^{\circ}$ \\
\hline 500 & $\mathrm{~Hz}$ & $(h 10)=$ & & 0.038 & $57.8^{\circ}$ \\
\hline 550 & $\mathrm{~Hz}$ & $(\ln 11)=$ & & 0.058 & $-1.9^{\circ}$ \\
\hline 600 & $\mathrm{~Hz}$ & $(h 12)=$ & & 0.048 & $-83-4^{\circ}$ \\
\hline 650 & $\mathrm{~Hz}$ & $(\mathrm{~h} 13)=$ & & 0.168 & $-13.5^{\circ}$ \\
\hline 700 & $\mathrm{~Hz}$ & $(\mathrm{~h} 14)=$ & & 0.038 & $112.7^{\circ}$ \\
\hline 750 & $\mathrm{~Hz}$ & $($ h15 $)=$ & & 0.108 & $142.8^{\circ}$ \\
\hline 800 & $\mathrm{~Hz}$ & $(\mathrm{~h} 16)=$ & & 0.038 & $88.6^{\circ}$ \\
\hline 850 & $\mathrm{~Hz}$ & $(\operatorname{h17})=$ & & 0.078 & $57.9^{\circ}$ \\
\hline 900 & $\mathrm{~Hz}$ & $(\ln 18)=$ & & 0.038 & $69.1=$ \\
\hline 950 & $\mathrm{~Hz}$ & $($ h19) $=$ & & 0.088 & $179.4^{\circ}$ \\
\hline
\end{tabular}

Figure 19. FFT analysis of phase A current after synchronization through ACF 


\section{CONCLUSION}

This paper describes various application of adaptive comb filter for signal analysis in power system applications. Several digital simulation tests are conducted to highlight the features of ACF such as simple structure, self adaptive to frequency, robust, immune to noise, high grade of accuracy and speed of response. Without loss of generality the results are compared and presented the waveforms, controlling parameters and numerical datas are depicited to show the feasiblity of the system. The ACF instantaneously tracks the parameter variation such as amplitude, frequency and phase smoothly and successfully.It also extracts and estimates the individual harmonic and reactive components faithfully.The $\mathrm{n}$ coupled parallel ACF units not only detect the parameter variation and to a greater extent it is used as a synchronizing tool to compensate the highly disorted signal resourcefully.

Table 1.Comparison of time domain parameters for EPLL and ACF with respect to sine waveform

\begin{tabular}{ccccc}
\hline Type of Estimator & Delay time $(\mathrm{S})$ & Rise time $(\mathrm{S})$ & Peak time(S) & Settling time $(\mathrm{S})$ \\
\hline EPLL & 0.08 & 0.13 & 0.2 & 0.4 \\
ACF & 0.02 & 0.08 & 0.1 & 0.1 \\
\hline
\end{tabular}

Comparison of time domain parameters for EPLL and ACF is shown in Table 1. By using ACF estimator, delay time is reduced from 0.08 to $0.02 \mathrm{sec}$; rise time is reduced from 0.13 to $0.08 \mathrm{sec}$; peak time is reduced from 0.2 to $0.1 \mathrm{sec}$; settling time is reduced from 0.43 to $0.1 \mathrm{sec}$; Hence, ACF is superior than EPLL. The future task is to implement in Field Programmable Gate Array (FPGA) to enhance the features of the system.

\section{REFERENCES}

[1] Deepa S, Vanaja Ranjan P. "Processing of Harmonics and Interharmonics using Comb Filters". European Journal of Scientific Research. vol. 69, no. 1, pp. 111-136, 2012.

[2] Alaa Abdulhady Jaber, Robert Bicker, "Development of a Condition Monitoring Algorithm for Industrial Robots based on Artificial Intelligence and Signal Processing Techniques", International Journal of Electrical and Computer Engineering, vol. 8 no 2, pp.996-1009, 2018.

[3] Michael R. Portnoff, "Time Frequency Representation of Digital Signals an Systems Based on Short Time Fourier Analysis", IEEE Trans. on ASSP. Vol. 28 no 1, pp.55-69, 1980.

[4] Michael S. Richman, Thomas W. Parks and Ramachandra G. Shenoy, "Discrete -Time, Discrete-Frequency, TimeFrequency Analysis", IEEE Trans. on Signal Processing.vol. 46 no 6, pp.1517-1527, 1998.

[5] Emad A. Awada, "Hilbert Based Testing of ADC Differential Non-linearity Using Wavelet Transform Algorithms", International Journal of Electrical and Computer Engineering. Vol. 8 no. 6, pp.5071-5079, 2018.

[6] P. R. Pattanaik, S. Pati, S. K. Sanyal, "Transient Monitoring Function based Fault Classifier for Relaying Applications," International Journal of Electrical and Computer Engineering. Vol. 8 no. 6, pp.4089-4095, 2018.

[7] Math H.J. Bollen, IreneY.H. Gu, Surya Santoso, Mark F. McGranaghan, Peter A. Gossley, Moises V. Riberio and Paulo F. Ribeiro, "Assessing power system quality using signal processing techniques", IEEE Signal Processing Magazine. pp. 12-31, 2009.

[8] Martin Valtierra-Rodriguez, David Granados-Liberman, Jose E. Torres-Fernandez, "A new methodology for tracking and instantaneous characterization of voltage variations". IEEE Trans.on Instrumentation and Measurement. vol 65, no. 7, pp. 1596-1604, 2016

[9] Murugesan P, Sharmeela C, "Multi-Class SVM for monitoring power quality disturbance using MRA". International Journal of Advanced Research in Basic Engineering Sciences and Technology. vol 3 no. 2, pp.16-26, 2017.

[10] Suja S, Jovitha Jerome, "Pattern recognition of power signal disturbances using S Transform and TT Transform". International Journal of Electrical Power and Energy Systems. vol.32, pp.37-53, 2010.

[11] M. Latfaoui, F. Bereksi Reguig, "Time frequency analysis of ultrasound Doppler signal by S-transform and WignerVille distribution", Indonesian Journal of Electrical Engineering and Computer Science.vol. 14 no.3, pp.1220-1227, 2019.

[12] Dash PK, Swain DP, “An Adaptive Linear Combiner for On-Line Tracking of Power System Harmonics.” IEEE Trans. Power Systems. vol. 11 no. 4, pp.1730-1735, 1996.

[13] A. A. Abdelsalam, A. A. Eldesouky, and A. A. Sallam, "Characterization of power quality disturbances using hybrid technique of linear Kalman filter and fuzzy-expert system”, Electr. Power System Res., vol.83 no. 1, pp. 41-50, 2012.

[14] K. Dhineshkumar, C. Subramani, "Kalman Filter Algorithm for Mitigation of Power System Harmonics". International Journal of Electrical and Computer Engineering.vol. 8 no.2, pp.771-779, 2018 .

[15] Carvalho JR, Riberio MV, "A PLL-Based Multirate Structure for time-varying Power System Harmonics/ Interharmonics Estimation”. IEEE Trans. Power Delivery. Vol 24 no.4, pp.1789-1800, 2009.

[16] Yang Y, Hadjidemetriou L, "Benchmarking of Phase Locked Loop Based Synchronization Techniques for GridConnected Inverter Systems”. Digital Explorer, 2013.

[17] Ghartemani MK, Iravani, MR “A. Signal Processing Module for Power System Applications”. IEEE Trans. Power 
Deli.,vol.18 no 4, pp.1118-1126, 2003.

[18] Gharatemani MK, Iravani MR, "A Nonlinear Adaptive Filter for Online Signal Analysis in Power Systems: Aplications", IEEE Trans. Power Delivery. Vol. 17 no. 2, pp.617-622, 2002

[19] Gharatemani MK, Iravani MR, "Time Domain Signal Analysis Using Adaptive Notch Filter. IEEE Trans. Signal Processing. Vol. 55 no. 1, pp.85-93, 2002.

[20] Mojiri M, Bakhshai AR, "Estimation of n Frequencies Using Adaptive Notch Filter". IEEE Trans. Circuits and systems. Vol. 54 no.4, pp.338-342, 2002.

[21] Tarek M, Mekhilef S, “Application of Adaptive Notch Filter for Harmonics Currents Estimation”. International Power Engineering Conference.2007, pp. 1236-1238.

[22] Yazdani D, Bakhshai A, "A three phase adaptive notch filter-based approach to harmonics/reactive current extraction and harmonic decomposition”. IEEE Trans. Power Electronics.vol.25 no.4, pp.914-923, 2010.

[23] Cheng-I Chen, Gray W. Chang, Virtual Instrumentation and Educational Platform for Time-Varying Harmonics and Interharmonics Detection. IEEE Trans. Industrial Electronics. vol.57 no.10, pp.3334-3342, 2010.

[24] Hasan WS, Ayyappa Dora J, "Adaptive Notch Filter based Fuzzy Controller for Synchronization of Grid with Renewable Energy”. IEEE Digital Explorer. pp.122-127, 2015.

[25] Thangaraj K, Subramaniam N P, Narmada R, Uma Mageswari M, "Analysis of harmonics using wavelet technique", International Journal of Eectrical and Computer Engineering. Vol. 9 no. 3 pp.1669-1675, 2019.

[26] Ibrahim Alhamrouni, Wira Wahab, Mohamed Salem, Nadia H. A. Rahman, Lili Awalin, "Modeling of Micro-grid with the consideration of total harmonic distortion analysis", Indonesian Journal of Electrical Engineering and Computer Science. vol15 no 2, pp. 581-592, 2019;

[27] Murugesan P and Sharmeela C, “An Adaptive Phase Locked Loop for Processing Power Quality Events”, IEEE Digital Explorer. Pp.269-274, 2018. 